\title{
A COLABORAÇÃo PREMIADA COMO MECANISMO EFICAZ NO COMBATE A CORRUPÇÃO: UMA REVISÃO INTEGRATIVA DA LITERATURA
}

\section{ESTADO DA ARTE}

LEITE, Michael Douglas Sousa ${ }^{1}$

CAVALCANTE, Matheus Lôbo ${ }^{2}$

BANDEIRA, Gutemberg de Oliveira ${ }^{3}$

LINHARES, Rafael Silva ${ }^{4}$

SANTOS, Lidiane Lopes Queiroga ${ }^{5}$

MOURA, Wanessa Arnaud ${ }^{6}$

${ }^{1}$ Mestrando em Sistemas Agroindústrias - UFCG, Pós-Graduado em Docência do Ensino Superior, Graduado em Administração - UFCG.

2 Mestrando em Sistemas Agroindústrias - UFCG, Pós-Graduado em Direito Administrativo e Gestão Pública (Urca); Especialista em Língua Portuguesa e Literatura, Bacharel em Direito (Urca/Campus Iguatu).

3 Mestrando em Sistemas Agroindústrias - UFCG, Pós-Graduado em Direito Administrativo e gestão pública pelas Faculdades Integradas de Patos (UNIFIP), Graduado em Direito (UFCG).

4 Mestrando em Sistemas Agroindústrias - UFCG, Graduado em Direito pela Faculdades Integradas de Patos (FIP).

${ }^{5}$ Mestranda em Sistemas Agroindústrias - UFCG, Graduada em Serviço Social.

${ }^{6}$ Mestranda em Sistemas Agroindústrias - UFCG, Pós-Graduada em Fisioterapia Traumato-ortopédica e Desportiva, Graduada em Fisioterapia (FIP). 


\section{MARQUES, Agilio Toma ${ }^{7}$}

LEITE, Michael Douglas Sousa. Et al. A colaboração premiada como mecanismo eficaz no combate a corrupção: Uma revisão integrativa da Literatura. Revista Científica Multidisciplinar Núcleo do Conhecimento. Ano 05, Ed. 11, Vol. 13, pp. 149 170. Novembro de 2020. ISSN: 2448-0959, Link de acesso:https://www.nucleodoconhecimento.com.br/sem-categoria/a-colaboracaopremiada

\section{RESUMO}

O presente artigo buscou averiguar através da revisão integrativa da literatura o instituto da colaboração premiada no Direito Penal brasileiro, verificando se a colaboração, consiste em meio eficiente de alcance de provas e combate a corrupção. A colaboração premiada faz parte de uma política nova de combate à criminalidade, fazendo com que produza o estímulo ao arrependimento dos que já se submergiram na prática de crime. Sabe-se, que o Brasil se localiza num cenário em que um dos desafios maiores das autoridades, tem sido o combate a corrupção e violência. Nos últimos anos, o que se tem visualizado é o desenfreado aumento da violência e corrupção, sem que o Estado desempenhe com eficiência e eficácia o que a Constituição the atribui enquanto responsabilidade. Para chegar ao alcance dos objetivos, a presente pesquisa trata-se de Estudo do tipo Revisão Integrativa da Literatura. Para levantamento dos artigos foram utilizadas as seguintes bases: Biblioteca Científica Eletrônica em Linha (Scielo), Google Acadêmico, Portal de Periódicos CAPES/MEC e Base de dados na área de Direito (BCE) e os descritores "Colaboração Premiada", "Corrupção" e "Lei 12.850". A princípio, a busca pelos descritores foi dada individualmente, utilizando-se posteriormente o cruzamento a partir do operador booleano "and". Os resultados mostraram que a colaboração premiada se denota como um instituto jurídico que, por meio das informações dos delatores, labora como uma figura de obtenção da verdade. Além disso a delação, é

\footnotetext{
${ }^{7}$ Mestrando em Sistemas Agroindústrias - UFCG, Especialista em Direito Processual Civil, Graduado em Direito.
} 
um instituto poderoso no enfretamento às organizações criminosas, pois, ainda na fase de investigação o colaborador, além de confessar os seus crimes para as autoridades, evade a consumação de outras violações, bem como auxilia a polícia e o Ministério Público nas suas atividades no recolhimento de provas contra os outros coautores, possibilitando as suas prisões.

Palavra-chave: Colaboração Premiada, Lei 12.850, corrupção, Administração Pública.

\section{INTRODUÇÃO}

O presente artigo busca averiguar, através da revisão integrativa da literatura o instituto da colaboração premiada no Direito Penal brasileiro, verificando se a colaboração, consiste em meio eficiente de alcance de provas e combate a corrupção. O interesse pelo tema vem dos recentes acontecimentos no cenário político do país, impelidos pela imprevisibilidade das vias trilhadas pelas operações gigantescas policiais de combate ao crime, no setor público, pôs em uso, a delação premiada, bem como a sua compatibilidade segundo princípios que conduzem o direito processual penal.

Cavalcanti (2011) destaca que a colaboração Premiada está prevista na legislação brasileira, servindo para incentivar uma eventual ação delituosa a expor todo esquema criminoso e identificar os envolvidos, sendo em recompensa proporcionado ao delator benefícios que diretamente interferem em sua sanção penal.

A colaboração premiada faz parte de uma política nova de combate à criminalidade, perfazendo com que produza o estímulo ao arrependimento dos que já se submergiram na prática de crime. Surgida para combater principalmente a criminalidade aparelhada, a delação passou a ter uma relevância maior e abrangência com o uso para outras modalidades delitivas (CAVALCANTI, 2011).

Em termos, se exige do delator a efetiva e decisiva influência na instrução processual, possibilitando a colheita de provas que basearão para a repressão futura penal, necessitando o mesmo, propor de ampla maneira a materialidade dos crimes, sendo que o envolvido possa informar ou esclarecer todas as peculiaridades, modos atuante, 
localização do produto, identificar os integrantes da ação ilícita, fornecer a localidade onde possam ser encontrados os coautores, com a finalidade de que as autoridades competentes possam desarticular e punir os envolvidos (CAVALCANTI, 2011).

A colaboração nunca esteve tão evidente no Brasil. Para ser ter uma ideia, dados da Polícia Federal (2017) revelam que o número das operações de enfretamento à corrupção aumentou em mais de (400\%) em cinco anos, passando de 57 operações em 2013, para cerca de 287 em 2017. Nesse período, o número de prisões chegou a 1.946 e de investigação a 622. Centenas de sujeitos foram presos por cometer crimes como: recebimento de vantagem indevida, fraude, corrupção, lavagem de dinheiro, formação de quadrilha, obstrução da Justiça e entre outros.

Inserra (2018) relata que a tendência da expansão da justiça criminal negocial é inquestionável e perceptível no cenário internacional e brasileiro do processo penal. Em presença da crise perene do sistema de persecução estatal e do aumento da abrangência do Direito Penal como organismo de controle social, fenômenos incentivados por buscas ilusórias de soluções momentâneas para complexos problemas, a escolha por alternativas procedimentais e por ferramentas de aceleração processual tem se sobressaído nas reformas normativas e na prática da justiça criminal.

$\mathrm{O}$ autor supramencionado estabelece os conceitos de justiça criminal negocial e consensual e suas relações com os espaços de oportunidade, caracterizados como pressupostos da delação premiada e dos outros institutos simbólicos de tal panorama (INSERRA, 2018). Ademais, esboçar-se-á a semelhança e a distinção entre barganha e colaboração premiada, visando o estabelecimento das premissas teóricas que guiam estes conceitos e seus limites dentro do processo penal. Também serão apontadas e estudadas as normativas internacionais que visam incentivar a aplicação dos mecanismos de colaboração no processo penal (VASCONCELLOS, 2017).

Sabe-se que o Brasil se encontra num cenário em que um dos desafios maiores das autoridades, tem sido o combate a corrupção e violência. Nos últimos anos, o que se tem visualizado é o desenfreado aumento da violência e corrupção, sem que o Estado 
desempenhe com eficiência e eficácia o que a Constituição Ihe atribui enquanto responsabilidade (BITTAR, 2011). Podem ser apontadas inúmeras razões como fatores que revelam a ineficiência no cumprimento do obrigação de proteção que o Estado tem perante a sua população; no entanto, a pretensão se faz não em denunciar os aludidos fatores; contudo, em discorrer a respeito do instituto da colaboração apontando-o como um ferramenta da política criminal em aferro às dificuldades tradicionais meios investigativos e, assim, um instrumento para reduzir os números da criminalidade organizada (SANTOS; ROCHA; VIALI, 2018).

Foi em razão dessa questão que o instituto da colaboração foi trazido para o Brasil, após a sua demonstração prática que se deu a partir de experiências que foram bem sucedidas em outros países, cuja criminalidade é ainda mais abrangente. Em tais nações, em especial Estados Unidos e Itália, o instituto de direito analisado tem sido de grande valia, por consequente eficiente para o efetivo combate do crime organizado (MENDONÇA, 2013).

Essa medida insere-se em um campo que contém a colaboração, o arrependimento eficiente e posterior, a desistência, a confissão, dentre diferentes institutos que disponibilizam prêmio segundo um determinado comportamento do acusado (LOPES, 2018).

Assim, em tempos de operação como a Lava Jato, à alcance que despontam novos indivíduos, envolvidos com o esquema de desvio de dinheiro e corrupção, amplia-se o número de acordos firmados de colaboração com investigados em troca de suas penas serrem aliviadas (DO CARMO; FÁVERO, 2017).

Do Carmo e Fávero (2017) relatam que a corrupção é um dos problemas mais comuns que as nações de todo o mundo vêm enfrentando. Seu caráter é social e estatal de modo eminente destrutivo, pois detém potencialidade ampla de adaptações e ainda resistência ao aparato e ao controle do Estado.

A colaboração premiada faz parte de vários mecanismos de combate ao crime, sendo usado em vários países, pois tem mostrando-se ser um efetivo meio de dissipação de 
organizações delituosas, sendo visualizada como uma técnica importante investigativa para combater o crime organizado (GOMES; SILVA, 2015).

O principal objetivo na escolha do tema é expor fundamentos e argumentos que nos trazem a compreensão de que a Colaboração Premiada é altamente eficaz em seu intuito de combater o crime organizado.

Destarte, é notório mostrar como a colaboração premiada é capaz de desestabilizar uma organização criminosa colocando em risco toda sua estrutura. Apresentar como ela é capaz de traçar caminhos que simultaneamente direcionam toda a investigação para o escalão das organizações. E analisar a colaboração premiada como método capaz de adiantar significativamente os resultados da investigação.

\section{MATERIAL E MÉTODOS}

Para chegar ao alcance dos objetivos a presente pesquisa utilizou a metodologia da Revisão Integrativa da Literatura, no qual foi elaborado através de seis etapas: a seleção do tema a ser abordado; a determinação dos critérios voltados a seleção da amostra; a definição das características da pesquisa original; a verificação dos dados; a interpretação dos resultados e a apresentação da revisão. (MENDES, 2008).

A pesquisa foi construída com bases nestas problemáticas: Realmente a colaboração premiada é eficaz no combate a corrupção? prova alguma coisa? Ela é capaz de embasar uma sentença condenatória?

Para levantamento dos artigos foram utilizadas as seguintes bases: Biblioteca Científica Eletrônica em Linha (Scielo), Google Acadêmico, Portal de Periódicos CAPES/MEC e Base de dados na área de Direito (BCE) e os descritores "Colaboração Premiada", "Corrupção" e "Lei 12.850". A princípio, a busca pelos descritores foi dada individualmente, utilizando-se posteriormente o cruzamento a partir do operador booleano "and". Desse modo, para a seleção da amostra, foram válidos os seguintes critérios de inclusão: artigos publicados no idioma português, no período de 2007 a 2019, que retrataram a temática em estudo. Sendo assim, foram excluídos aqueles 
que fugiam da faixa de tempo e com idioma divergente. A tabela 1 ilustra a estrutura metodológica utilizada.

Tabela 1: Publicações encontradas entre os anos de 2007 e 2019 nas bases de dados.

\begin{tabular}{|c|c|c|c|c|}
\hline \multirow[t]{2}{*}{ DESCRITORES } & \multicolumn{3}{|c|}{ BASE DE DADOS } & \multirow[b]{2}{*}{ BCE } \\
\hline & SCIELO & $\begin{array}{l}\text { Google } \\
\text { Acadêmico }\end{array}$ & $\begin{array}{l}\text { CAPES/ } \\
\text { MEC }\end{array}$ & \\
\hline Colaboração Premiada & 142 & 4820 & 30 & 316 \\
\hline Corrupção & 240 & 170000 & 2051 & 9509 \\
\hline Lei 12.850 & 2 & 2180 & 11 & 112 \\
\hline $\begin{array}{l}\text { Colaboração Premiada and } \\
\text { Corrupção }\end{array}$ & 3 & 4100 & 7 & 65 \\
\hline Corrupção and Lei 12.850 & 12 & 1170 & 1 & 20 \\
\hline $\begin{array}{l}\text { Colaboração Premiada and Lei } \\
12.850\end{array}$ & 16 & 938 & 1 & 30 \\
\hline Todos & 3 & 2 & 1 & 4 \\
\hline
\end{tabular}

Fonte: Dados da Pesquisa, 2020.

O processo de busca dos artigos seguiu às especificidades de todas as bases de dados apresentadas anteriormente, enquanto a seleção dos mesmo se baseou nos seguintes critérios: obediência à temática da pesquisa, de modo a fornecer informações precisas à questão norteadora do estudo, descritos no idioma português, além de estar enquadrado no período de tempo proposto acima, e permitir a acessibilidade ao seu conteúdo completo.

A realização do levantamento bibliográfico aconteceu nos meses de janeiro e fevereiro de 2020. Diante dos requisitos supramencionados e excluindo-se os artigos repetitivos nas bases de pesquisa utilizadas, foram selecionados dez artigos, dos quais foram 
submetidos a releituras, a fim de concretizar uma análise interpretativa direcionada pela questão condutora.

Na tabela 2 abaixo são apresentadas as características dos artigos incluídos na Revisão Integrativa.

Tabela 2: Apresentação das características dos artigos incluídos na Revisão Integrativa

\begin{tabular}{|c|c|c|c|c|}
\hline Título & Autor(es) & $\begin{array}{l}\text { Ano / } \\
\text { País }\end{array}$ & $\begin{array}{l}\text { Delineamento } \\
\text { do Estudo }\end{array}$ & Desfechos \\
\hline $\begin{array}{lr}\text { A colaboração } \\
\text { premiada } \\
\text { terceira via } \\
\text { direito penal no } \\
\text { enfrentamento } \\
\text { corrupção } \\
\text { administrativa } \\
\text { organizada. }\end{array}$ & $\begin{array}{l}\text { SILVA, M. R. } \\
\text { da }\end{array}$ & $\begin{array}{l}2017 / \\
\text { Brasil }\end{array}$ & $\begin{array}{l}\text { Estudo } \\
\text { Documental e } \\
\text { Bibliográfico. }\end{array}$ & $\begin{array}{l}\text { Os acordos de } \\
\text { colaboração } \\
\text { premiada vêm } \\
\text { exteriorizando um } \\
\text { direito penal de } \\
\text { terceira via e que há } \\
\text { com isso viabilidade } \\
\text { de violações à } \\
\text { legalidade penal, à } \\
\text { proporcionalidade e } \\
\text { à isonomia no } \\
\text { enfrentamento à } \\
\text { corrupção } \\
\text { administrativa. }\end{array}$ \\
\hline $\begin{array}{l}\text { Lei de Organização } \\
\text { Criminosa: } \\
\text { colaboração } \\
\text { premiada e a } \\
\text { responsabilidade do } \\
\text { estado na prevenção }\end{array}$ & $\begin{array}{l}\text { CAMACHO, } \\
\text { M. G.; LEAL, } \\
\text { T. de C. P. V. }\end{array}$ & $\begin{array}{l}2015 \\
\text { Brasil }\end{array}$ & $\begin{array}{l}\text { Estudo } \\
\text { descritivo } \\
\text { analítico. }\end{array}$ & $\begin{array}{l}\text { O dispositivo legal } \\
\text { trouxe consigo um } \\
\text { rol de meios } \\
\text { probatórios } \\
\text { altamente efetivos, } \\
\text { dentre eles a } \\
\text { colaboração }\end{array}$ \\
\hline
\end{tabular}


e combate ao crime

organizado.

\begin{tabular}{|c|c|c|c|c|}
\hline & & & & $\begin{array}{lr}\text { persecução penal } \\
\text { capacidade de } \\
\text { opor-se a essa } \\
\text { espécie de } \\
\text { criminalidade, pois, } \\
\text { conforme exposto, } \\
\text { sua complexidade e } \\
\text { transnacionalidade } \\
\text { exigem métodos } \\
\text { excepcionais de } \\
\text { confronto }\end{array}$ \\
\hline $\begin{array}{l}0 \text { instituto da } \\
\text { delação premiada } \\
\text { como forma de } \\
\text { obtenção da verdade }\end{array}$ & $\begin{array}{l}\text { ALVES, S. } \\
\text { P.; SILVA, E. } \\
\text { G. }\end{array}$ & $\begin{array}{l}\text { 2017/ } \\
\text { Brasil }\end{array}$ & $\begin{array}{l}\text { Estudo } \\
\text { descritivo e } \\
\text { documental. }\end{array}$ & $\begin{array}{l}\text { Identificou que o } \\
\text { instituto negocial } \\
\text { penal da delação } \\
\text { premiada se coloca } \\
\text { como um instituto } \\
\text { jurídico que, por } \\
\text { meio das } \\
\text { informações dos } \\
\text { delatores, funciona } \\
\text { como uma forma de } \\
\text { obtenção da } \\
\text { verdade. }\end{array}$ \\
\hline $\begin{array}{l}\text { Do instituto da } \\
\text { delação premiada: } \\
\text { conceito, } \\
\text { abordagem } \\
\text { comparativa, } \\
\text { evolução legislativa }\end{array}$ & $\begin{array}{l}\text { VIEIRA, R. } \\
\text { D.; } \\
\text { MORILLAS, } \\
\text { J. P }\end{array}$ & $\begin{array}{l}2018 \\
/ \\
\text { Brasil }\end{array}$ & $\begin{array}{l}\text { Pesquisa } \\
\text { Bibliográfica } \\
\text { e } \\
\text { exploratório. }\end{array}$ & $\begin{array}{l}\text { A delação, é um } \\
\text { poderoso instituto } \\
\text { no combate às } \\
\text { organizações } \\
\text { criminosas, pois } \\
\text { ainda na fase de }\end{array}$ \\
\hline
\end{tabular}




\section{no Brasil e posicionamentos doutrinários.}

\begin{tabular}{|c|c|c|c|c|}
\hline $\begin{array}{l}\text { Enfrentamento do } \\
\text { crime organizado } \\
\text { por meio da delação } \\
\text { premiada. }\end{array}$ & $\begin{array}{l}\text { SILVA, A. V. } \\
\text { da.; } \\
\text { BORGES, D. } \\
\text { M. }\end{array}$ & $\begin{array}{l}\text { 2018/ } \\
\text { Brasil }\end{array}$ & $\begin{array}{l}\text { Pesquisa } \\
\text { Bibliográfica, } \\
\text { do tipo } \\
\text { exploratório e } \\
\text { qualitativo. }\end{array}$ & $\begin{array}{l}\text { Através da Lei } \\
\text { 12.830/13, trouxe } \\
\text { algo inovador ao } \\
\text { combate estatal do } \\
\text { crime organizado: a } \\
\text { delação } \\
\text { colaboração } \\
\text { premiada. } \\
\text { utilização deste } \\
\text { instrumento tem } \\
\text { sua relevância e } \\
\text { utilidade no campo } \\
\text { da persecução }\end{array}$ \\
\hline
\end{tabular}

investigação

criminal

0

colaborador, além

de confessar seus

crimes para as

autoridades, evita a consumação de outras infrações, bem como auxilia concretamente a polícia e o Ministério Público nas suas atividades de recolher provas contra os demais coautores, possibilitando suas prisões.

Através da Lei

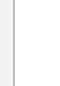




\begin{tabular}{|c|c|c|c|c|}
\hline & & & & $\begin{array}{l}\text { penal, visando ao } \\
\text { combate destemido } \\
\text { de organizações } \\
\text { criminosas, o que é } \\
\text { altamente salutar } \\
\text { para os interesses } \\
\text { da coletividade. }\end{array}$ \\
\hline $\begin{array}{l}\text { A delação premiada } \\
\text { no combate ao crime } \\
\text { organizado. }\end{array}$ & GREGHI, F. & 2007/ & $\begin{array}{l}\text { Pesquisa } \\
\text { Bibliográfica, } \\
\text { exploratório. }\end{array}$ & $\begin{array}{l}\text { A delação premiada } \\
\text { é uma forma } \\
\text { aconselhável de } \\
\text { obtenção de provas } \\
\text { que, se bem } \\
\text { empregada, perfaz- } \\
\text { se num excelente } \\
\text { instrumento de } \\
\text { efetivo combate à } \\
\text { criminalidade } \\
\text { organizada. }\end{array}$ \\
\hline $\begin{array}{l}\text { A colaboração } \\
\text { premiada e processo } \\
\text { penal brasileiro: } \\
\text { Uma análise crítica. }\end{array}$ & $\begin{array}{l}\text { LUZ, A. M. } \\
\text { de A.; et al. }\end{array}$ & 2017/ & $\begin{array}{l}\text { Estudo } \\
\text { descritivo } \\
\text { analítico. }\end{array}$ & $\begin{array}{l}\text { Frisa a impotência } \\
\text { do "aparelho } \\
\text { estatal" em aliar-se } \\
\text { ao criminoso para } \\
\text { poder receber } \\
\text { informações que } \\
\text { deveriam ser } \\
\text { obtidas pela pronta } \\
\text { atuação dos seus } \\
\text { órgãos } \\
\text { investigatórios. }\end{array}$ \\
\hline
\end{tabular}




\begin{tabular}{|c|c|c|c|c|}
\hline $\begin{array}{ll}\text { A eficácia } & \text { do } \\
\text { instituto } & \text { da }\end{array}$ & $\begin{array}{l}\text { SANTOS, L. } \\
\text { A.; ROCHA, } \\
\text { P. G. G.; } \\
\text { VIALI, F. C. } \\
\text { A. }\end{array}$ & 2018/ & $\begin{array}{l}\text { Estudo } \\
\text { Documental e } \\
\text { Bibliográfico. }\end{array}$ & 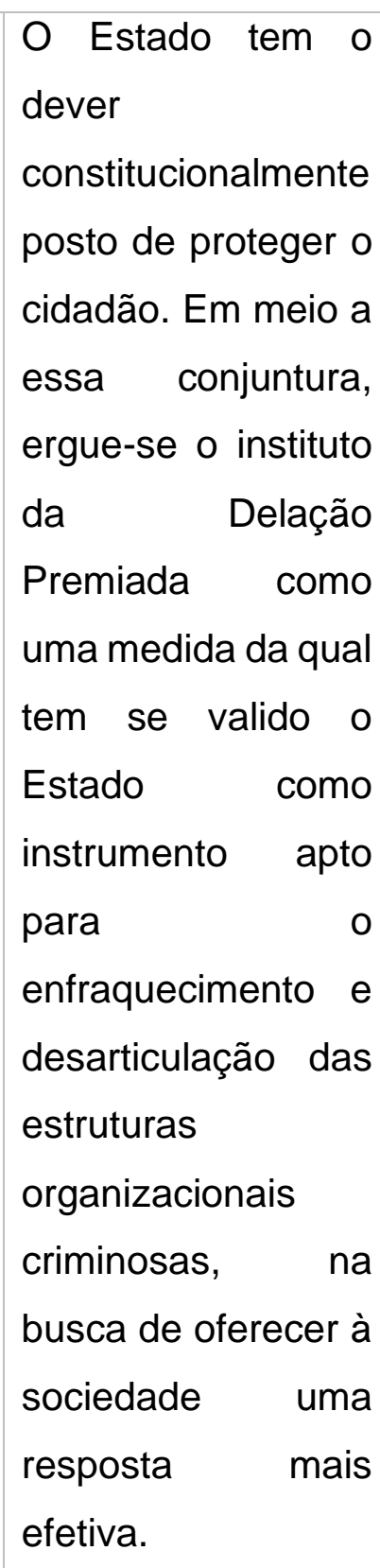 \\
\hline $\begin{array}{lr}\text { Delação } & \text { premiada } \\
\text { desafios } & \text { e } \\
\text { perspectivas } & \text { no } \\
\text { Brasil. } & \end{array}$ & $\begin{array}{l}\text { ARAUJO, D. } \\
\text { M. de.; } \\
\text { CARVALHO, } \\
\text { G. B. V. de. }\end{array}$ & $\begin{array}{l}\text { 2015/ } \\
\text { Brasil }\end{array}$ & $\begin{array}{l}\text { Estudo } \\
\text { descritivo } \\
\text { analítico. }\end{array}$ & $\begin{array}{l}\text { Os desafios da } \\
\text { delação premiada } \\
\text { no âmbito da nova } \\
\text { Lei das } \\
\text { organizações } \\
\text { criminosas, } \\
\text { demonstrando o } \\
\text { impacto que o crime }\end{array}$ \\
\hline
\end{tabular}




\begin{tabular}{|c|c|c|c|c|}
\hline & & & & $\begin{array}{l}\text { organizado teve } \\
\text { através da delação, } \\
\text { mostrando algumas } \\
\text { operações } \\
\text { conhecidas } \\
\text { nacionalmente } \\
\text { trazendo à tona a } \\
\text { operação Lava jato, } \\
\text { demonstrando o } \\
\text { quanto a delação } \\
\text { premiada vem } \\
\text { contribuindo no } \\
\text { desfecho dessa } \\
\text { operação. }\end{array}$ \\
\hline $\begin{array}{l}\text { A colaboração } \\
\text { premiada como } \\
\text { instrumento de } \\
\text { política criminal: a } \\
\text { tensão em relação } \\
\text { às garantias } \\
\text { fundamentais do réu } \\
\text { colaborador. }\end{array}$ & AIRES, M. T. & $\begin{array}{l}2017 / \\
\text { Brasil }\end{array}$ & $\begin{array}{l}\text { Estudo } \\
\text { Documental e } \\
\text { Bibliográfico. }\end{array}$ & $\begin{array}{l}\text { A expressão da } \\
\text { justiça criminal } \\
\text { negociada não deve } \\
\text { ocorrer de modo a } \\
\text { realizar-se uma } \\
\text { mera importação } \\
\text { jurídica, seja das } \\
\text { experiências } \\
\text { europeias, seja das } \\
\text { origens anglo- } \\
\text { saxãs. A previsão } \\
\text { da colaboração } \\
\text { premiada deve ser } \\
\text { coerente com } \\
\text { Ordenamento } \\
\text { Jurídico brasileiro, } \\
\text { como também deve }\end{array}$ \\
\hline
\end{tabular}




\begin{tabular}{|l|l|l|}
\hline & & $\begin{array}{l}\text { estar adequada à } \\
\text { tradição jurídica do } \\
\text { Brasil. }\end{array}$ \\
\hline
\end{tabular}

Fonte: Dados da Pesquisa, 2020.

Os resultados obtidos foram agrupados em duas categorias temáticas, sendo que a primeira relata colaboração premiada na legislação brasileira, trazendo um histórico do surgimento acerca das primeiras leis e sua constitucionalidade e a segunda a eficácia da colaboração premiada no combate ao crime organizado. A análise consistiu em extrair a visão dos autores, buscando na literatura os trabalhos que descrevem a colaboração premiada como mecanismo eficaz no combate a corrupção.

\section{A COLABORAÇÃO PREMIADA NA LEGISLAÇÃO BRASILEIRA E SUA CONSTITUCIONALIDADE}

O presente tópico procura mostrar como funciona a delação premiada no Brasil e os seus principais problemas relacionados falta de um procedimento específico, graças as várias legislações esparsas que normatizam o instituto da delação premiada.

No Brasil, a colaboração premiada segundo Luz et al. (2017) é vetusta na Legislação, possui previsão, desde o século XVII, nas Ordenações Filipinas, nos Títulos IV e CXVI precisamente que tratavam, sobre os crimes de Lesa Magestade e o benefício aos criminosos que delatarem. No Título VI do Código Filipino, tratava da delação premiada, onde se perdoaria os malfeitores que derem outros à prisão e tinha poder, inclusive, para premiar, com perdão, criminosos que delatassem delitos alheios.

$\mathrm{Na}$ história brasileira, existiram vários episódios em que a colaboração foi utilizada, Luz et al. (2017) citam a inconfidência Mineira, onde, em 1789, tempo em que a nação era submissa aos lusitanos, o então Coronel Joaquim Silvério delatou os sujeitos envolvidos, na Conjuração Mineira, dentre o mártir Tiradentes. Em contrapartida, o delator teve o perdão total da dívida diante a Fazenda Real. 
Greghi (2007) destaca que hoje me dia, não existe uma única lei acerca das hipóteses de colaboração premiada. Destaca-se, um desregrado emaranhado e assistemático de normas propostas ao tratamento do instituto, do qual decorrem questionamentos diversos.

Colaborando Araújo e Carvalho (2015) relatam que por vários anos a legislação se manteve inerte quanto sua regulamentação, vindo a ser outorgada apenas na década de 1990 a partir da promulgação da lei dos crimes hediondos, a lei $n^{\circ} 8.072$ que foi a primeira lei, que expressamente cuidou da colaboração premiada, cujo art. 8o, parágrafo único, começou a prever que "o participante e o associado que denunciar às autoridades o bando, permitindo o seu desmontar, terá a penalidade reduzida de um a dois terços" (BRASII, 1990).

Neste sentido, a Lei 8.072/1990, foi a que gizou os contornos primeiros da colaboração premiada, posteriormente, legislações inúmeras abrigaram-na em seus corpos. Greghi (2007) lembra que esta Lei, previu duas hipóteses de delação, ambas como causa de redução de pena. Na primeira estava contida na primitiva inserção do parágrafo 4ํ no artigo 159 do CP que dispunha: "se o crime for cometido por quadrilha ou bando, o coautor que denunciá-lo à autoridade, facilitando a libertação do sequestrado, terá a sua pena reduzida de um a dois terços". Posterior, a Lei 9.269/1996, alterou esse parágrafo, e hoje preceitua que: "se o crime for cometido em concurso, o concorrente que o denunciar à autoridade, facilitando a libertação do sequestrado, terá a sua pena reduzida de um a dois terços" (BRASII, 1996).

De acordo com o trabalho de Greghi (2007) a segunda hipótese da delação está na Lei dos Crimes Hediondos, encontrando-se no do seu artigo 8ํㅜ parágrafo único como já foi citado por Araújo e Carvalho (2015). Tal preceito para Greghi (2007) na disciplina causa diminuição de penalidade, reclamando que algum dos integrantes da quadrilha, assumindo a sua devida responsabilidade penal, apresentando as informações à competência policial, judiciária ou ao representante do Ministério Público, com a finalidade de proporcionar o seu desarranjo. 
Para Vieira e Morillas (2018), não há dúvidas quanto à natureza da colaboração ou sobressaltos juridicamente, pois que é causa de diminuição da pena tanto no art. 8으, como no art. 1ㅜ, inciso IV (todos da Lei 8 072), o qual deu redação ao art. 159, caput e seus $\S \S 1^{\circ}, 2^{\circ}$ e $3^{\circ}$ do CP.

Antes da vigência da Lei 9269 de 1996, que trouxe em seu §4º do art. 159, Vieira e Morillas (2018), registram que o crime de extorsão mediante o sequestro, tinha, como natureza para o uso da colaboração, ser cometido em quadrilha/bando (necessário de mais de três pessoas). O que ocorreu foi a flexibilização dessa condição, podendo ser quem delata o agente em concurso eventual.

Araújo e Carvalho (2015) destacam em seu artigo que a colaboração premiada está prevista em diversos dispositivos legais, como no art. 159, §4ํㅡㄹ do Código Penal; na Lei ${ }^{\circ}$ 7.492/86, art. 25, §2º; na Lei n 8.137/90, art. 16; na Lei n` 9.613/98, com redação fornecida pela Lei oㅜ 12.683/12, art. 1ㅇ, § 5o; na Lei 9.807/99, arts. 13 e 14; na Lei no 11.343/06, art. 41, dentre outros.

Posterior a todas as demais, a nova lei das organizações criminosas, lei $n^{\circ} 12.850$ de 2013, trousse uma novidade consigo acerca do instituto, que foi o perdão e o não oferecimento de ação penal em determinados casos. A referida lei, trata do combate ao crime organizado, prevendo diversas medidas de repressão eficazes, por meio de uma investigação mais profícua e busca por meios de obtenção de prova.

Segundo Vieira e Morillas (2018), no capítulo II, da Lei mencionada, que aborda a investigação e meios de obtenção da prova, encontra-se o inovador termo assentado "colaboração premiada", no art. $3^{\circ}$, in verbis:

Art. $3^{\circ}$. Em qualquer fase da persecução penal, serão permitidos, sem prejuízo de outros já previstos em lei, os seguintes meios de obtenção de prova:

I- Colaboração premiada; [...] (BRASIL, 2013).

Em primeiro lugar, Camacho e Leal (2015) trazem uma reflexão de uma maneira sucinta, acerca do conceito de organização criminosa definido pela Lei № 12.850 de 
2013. De acordo com o exposto no art. $1^{\circ}, \S 1^{\circ}$, classifica-se organização criminosa a associação de quatro ou mais sujeitos, especificamente ordenada e marcada por divisão de tarefas, com a finalidade de obter vantagem seja de qualquer natureza, através de condutas criminosas, cujas penas máximas extrapolem quatro anos. $\mathrm{Na}$ verdade, a lei retrata o anseio do legislador de combater o aumento do crime organizado. É visualizando o aprimoramento dessas associações que, não obstante, camuflam suas práticas, sofisticam o aparato organizado de poder e distribuição das tarefas, tornam assim complexa o papel do Estado na identificação dos seus membros, dos delitos cometidos.

Luz et al. (2017) destacam que ao definir a caráter jurídico da colaboração premiada, o STF esquematizou os requisitos do acordo em três planos: existência, validade e eficácia. O voto do relator Ministro Dias Toffoli, unanimemente seguido pelo pleno, apontou que na esfera da existência deve-se atentar ao artigo 6으 da Lei 12.850 de 2013, de modo a se inferir que "esse acordo precisará ser realizo por escrito e contendo: 1) o relatório da colaboração e os possíveis resultados; 2) as condições da proposta do MP ou delegado de polícia; 3) a declaração do colaborador de aceitação; e iv) as assinaturas do representante do MP ou do delegado de polícia, do colaborador e do seu defensor". São indicados, portanto, requisitos externos para a formalização do documento que servira de base para a judicialização do acordo de colaboração premiada.

Já em relação ao plano da validade, os autores supramencionados relatam na visão do STF, aspectos subjetivos de verificação da vontade do colaborador e objetivos acerca do objeto negociado devem ser apurados, já que "o acordo de colaboração será somente válido se: 1) a declaração da vontade do colaborador for a) resultado de um processo volitivo; b) querida com a plena consciência da realidade; c) escolhida com a devida liberdade e d) deliberada sem má-fé; e 2) a seu finalidade for lícita, possível e determinado". Por fim, a esfera da eficácia se realizaria com o controle do acordo por meio da submissão à homologação judicial.

Assim, verifica-se que tanto no plano da existência quanto no da eficácia foram fixados requisitos de ordem meramente formal ou externa, não havendo muito o que se 
discutir acerca destes, de modo que aprofundaremos o estudo nos requisitos de validade do acordo, vez que são estes que efetivamente influenciarão na legitimidade ou não da colaboração.

No entanto, Silva (2017) faz uma crítica acerca da delação premiada, onde exprime a ideia que o estado foi ineficiente no combate a corrupção e a investigação pode ser lacônica, bastando, o Estado obter ajuda, com a oferecimento de um prêmio ao delator, que é interessado diretamente no desfecho desse litígio, por um simples sistema de trocas. Nesta visão, é que ocorre a discussão sobre a constitucionalidade da delação premiada ganha basilar interesse, porque se de um lado existe o pensamento de trazer um sujeito acusado de um delito, a atuar como auxiliador da justiça na penalidade de seus comparsas, por outro lado para alguns estudiosos há um agressão aos princípios fundamentais sobre os quais se alicerça o Estado Democrático de Direito.

Silva e Borges (2018) relatam que o direito é valorativo, podendo se comportar de entendimentos diversos e com racionalidade, apesar de balizar valores humanos, não sendo por si só um fenômeno que justifica uma imposição restritiva ao direito, e nesse mesmo aspecto existe o entendimento de que é preciso um mínimo de ética à vida em sociedade, onde é demandando que as relações humanas sejam adequadas às normas jurídicas e às normas morais.

Com outro pensamento, Araujo e Carvalho (2015) partem da doutrina que permite certa flexibilização da aplicação moral, apesar da delação premiada, apresentar um conteúdo suspeito, pode ser acolhido em um determinado ordenamento jurídico, para isso bastando, entender que a moral, justaposta ao mundo real, precisa ser ajustada às necessidades humanas.

Alves e Silva (2017) colaboram relatando que a colaboração está fundada na mais pura moral e ética e ainda, é de essência genuinamente pedagógica, pois instrui que não existe nada de nocivo em se arrepender dos erros passados, bem como em buscar reparar as ofensas feitas à sociedade. 
Na visão de Aires (2017), em virtude de beneficiar o Estado o instituto da colaboração premiada, deve pensar no preceito da moralidade administrativa, assegurado na Constituição de 1988 no seu artigo 37, o qual corrobora que todas as esferas da administração pública obedecerão, dentre os princípios, ao da moralidade para a tomada das suas decisões. Todavia, não é só na administração pública que precisa seguir e respeitar, e sim o particular também ao relacionar-se com o Estado, e o ato administrativo não terá que obedecer apenas à lei, mas também à ética da instituição, porque nem tudo aquilo que é legal é honesto.

Para Luz et al. (2017), existem aqueles que anteparam que a colaboração premiada é revestida da imoralidade, pela quebra de confiança, desagregando assim a sociedade e a ordem constitucional instituída. No entanto para os autores, falta levar em consideração que a própria investigação, é iniciada muitas vezes por uma delação vinda de qualquer pessoa, segundo autorização disposta no CPP em seu artigo 5ㅇ, parágrafo $3^{\circ}$. Tal direito é a figura do "delatio criminis", onde, qualquer do povo, na categoria de membro da sociedade, colabora com as autoridades, fornecendo informações sobre determinado um delito. Destarte, fica claro como exemplo que o Estado se fomenta da delação como fim para se encetar um processo criminal.

E de todo essa diagnostico, pode-se inferir que a colaboração, apesar de talvez caracterizar a traição/imoralidade, não pode ser tirada da legislação, pois sua inconstitucionalidade não prevalece de modo algum. Em todas as diversas teorias existentes, contra ou mesmo a favor, são muito bem justificadas, logicamente e juridicamente, e nenhuma dessas consegue separar a aplicabilidade da delação, pois é um instrumento usado na procura de um bem elevado para a sociedade, que é o combate à corrupção ou mesmo criminalidade, ficando claro a proteção cívica em desfavor do sujeito.

Frente ao relatado, a delação premiada carece ser aceita frente a sua constitucionalidade, como extraordinária ferramenta para o combate das organizações, e as possíveis eventuais inconstitucionalidades precisam ser avaliadas em caso concreto de forma única, respeitando sempre os direitos constitucionais dos indivíduos e da aplicação da justiça. 


\section{A EFICÁCIA DA COLABORAÇAO PREMIADA NO COMBATE AO CRIME ORGANIZADO}

O crime organizado é uma realidade muito antiga e crescente, que evoluiu conexa com a economia, tecnologia, política e etc. O Estado tem a responsabilidade pela repressão e prevenção, hoje em dia fracassada pelo grau de juntura, oriundos muitas vezes de uma simbiose com o próprio Estado.

Silva e Borges (2018) relatam que o crime organizado ganhou uma evolução significativa nos últimos anos. Atualmente uma das problemáticas maiores enfrentadas no âmbito criminal, está em descobrir quem são os participantes da organização criminosa, como é a hierarquia entre eles exercida, e qual função que cada um deles exerce dentro do grupo. Especialmente, no tocante aos grandes chefões das organizações, o que faz uma tarefa com grau elevado de dificuldade em identificá-los.

Camacho e Leal (2015) pontuam que a colaboração premiada tem sido uma arma imprescindível no enfretamento a este tipo de criminalidade. Essa arma para os autores auxilia a fortalecer as investigações, uma vez que abaliza rumos aos quais as investigações seguem. Sem a colaboração os investigadores (autoridade policial e MP) podem demorar mais de tempo para descobrirem as provas que corroborem na persecução criminal. Destarte, com a ajuda do colaborador a polícia tem uma economia de investigação, ganhando tempo e conseguindo desmontar a organização criminosa com mais rapidez (SILVA, 2016).

Colaborando Silva (2017) destaca que o próprio STF já se posicional favorável a colaboração premiada, onde uma das mais importantes ações foi no julgamento da Ação no470 Minas Gerais, que ficou conhecida nacionalmente como "mensalão". Alves e Silva (2017) destacam o entendimento da ministra Rosa Weber do STF, de que "o elemento ontológico da colaboração premiada não está na pessoa do colaborador e sim no pragmatismo, no interesse da persecução penal e na perspectiva de reduzir os danos causados pelos crimes que orientam a razão de ser da própria colaboração". 
Desse modo, entende-se que o valimento da colaboração, pode ser definido no proveito em que se tem com o pacto que é celebrado com o colaborador e a utilidade que este venha a ter na persecução criminal.

Outra benesse é destacado por Aires (2017) em seu trabalho, onde esse instituto proporciona o avanço do andamento dos processos, retirando um pouco da sobrecarga existente nas varas criminais no país, que estão repletas de réus aguardando julgamentos, esperando por meses ou anos para conseguirem, o que promete a garantia individual de ter um julgamento rápido, garantido pelo princípio da celeridade processual.

Cumpre ressaltar que, a visão de Santos; Rocha e Viali (2018) que a colaboração sozinha é insuficiente para ensejar uma condenação, ela precisa ser avaliada juntamente com outras provas geradas durante a persecução penal. Portanto, se tem que a colaboração esboçará de uma forma rápida o trabalho dos investigadores em procurarem por outros prova através da comprovação do que foi dito no acordo de colaboração.

Quando se relata em crime organizado ou organizações criminosas, Luz et al. (2017) ressaltam que existe um modus operandi complexo, isto é, armamento de porte grande, aparato tecnológico, relações com sujeitos ligadas ao Estado, sujeitos de influência no poder do país, o que facilitam a atuação desses criminosos. Desse modo, não é qualquer informação prestada pelo colaborador que vale um acordo, as informações por este repassadas precisam ser eficazes no combate ao crime organizado.

Desta forma, Silva (2017) pontua que a vantagem principal da utilização da colaboração é a ordem prática, uma vez que encontra-se diante a uma impossibilidade de se ter outras provas previstas nas investigações, e por não terem a desejada eficácia, uma vez que os membros das facções estão submetidos ao Código de Honra e a grande precisão de desmantelar a organização. 
Silva (2017) ainda traz uma análise sobre os dados fornecidos pelo Ministério Público onde na Operação Lava Jato, resultaram 06 prisões em flagrante, em de 2.500 procedimentos instaurados, 1.080 mandados de apreensões e buscas, 138 mandados de prisões temporárias, 230 mandados de conduções coercitivas e 120 mandados de prisões preventivas.

Corroborando com os dados supramencionados, Santos; Rocha e Viali (2018) destacam que o Ministério Público, também, das investigações originadas pela Operação, realizou 550 pedidos de cooperação internacional, sendo 270 pedidos ativos para 45 países e 280 pedidos passivos com 36 países; 11 acordos de leniência, 176 acordos de colaboração firmados com pessoas físicas, 82 acusações contra 347 pessoas, sendo que em 47 já houve sentença, pelos seguintes crimes: formação de organização, lavagem de ativos, corrupção, tráfico de drogas, crimes contra o sistema financeiro, entre outros.

Além disso, os autores supramencionados relatam mais de 215 condenações, contra 150 pessoas, contabilizando mais de 2.000 anos de pena; 16 empresas nacionais e 1 partido pedindo o pagamento de $R \$ 15$ bilhões; 10 acusações contra 50 pessoas de improbidade administrativa. Os crimes investigados envolvem pagamento de propina de cerca de $R \$ 40$ bilhões são alvo de recuperação por acordos de colaboração, sendo $R \$ 1$ Bilhão objeto de repatriação e $R \$ 3,2$ bilhões em bens já bloqueados.

Segundo ainda os autores supramencionados o Ministério Público Federal informa que os dados acima foram atualizados até outubro de 2018 (SILVA, 2017). Extrai-se dos resultados provenientes da Operação Lava jato, um expressivo corolário em números, que tornou a maior investigação contra a corrupção já realizada.

Abaixo destaca-se o trabalho de Silva (2017) em realizar um levantamento sobre os resultados que a colaboração proporcionou nesses últimos anos no Brasil. A tabela abaixo é apenas um resumo, pois na realidade a lista é bem vasta de delatores no Brasil. 
Tabela 3: Apresentação sobre os resultados que a colaboração proporcionou nesses últimos anos no Brasil.

\begin{tabular}{|c|c|c|c|}
\hline Colaborador/ & $\begin{array}{l}\text { Pena } \\
\text { fixada sem } \\
\text { redução }\end{array}$ & $\begin{array}{l}\text { Pena } \\
\text { negociada }\end{array}$ & $\begin{array}{l}\text { Quantias a título de repatriação de } \\
\text { valores/ multa }\end{array}$ \\
\hline Youssef & $\begin{array}{l}82 \text { anos e } \\
8 \\
\text { meses }\end{array}$ & $\begin{array}{l}3 \text { anos } \\
\text { (regime } \\
\text { fechado) }\end{array}$ & $\begin{array}{l}\text { Renunciou em favor da justiça } \\
\text { vários bens móveis ou imóveis, por } \\
\text { se tratarem de produtos e/ou } \\
\text { proveitos de crimes, bem como } \\
\text { quantia a quantia de } \mathrm{R} \$ \\
1.893 .410,00 \text { e U } \$ 20.000,00 \\
\text { apreendidos nas dependências da } \\
\text { empresa GFD Investimentos Ltda. }\end{array}$ \\
\hline $\begin{array}{l}\text { Mendonça } \\
\text { Neto Executivo } \\
\text { (Toyo Setal) }\end{array}$ & $\begin{array}{l}16 \text { anos e } \\
8 \\
\text { meses }\end{array}$ & $\begin{array}{l}4 \quad \text { anos } \\
\text { (regime } \\
\text { aberto) }\end{array}$ & $\begin{array}{l}\text { Comprometeu-se a pagar a título de } \\
\text { multa compensatória cível pelos } \\
\text { danos que reconhece } \\
\text { causados o valor de } R \$ \\
10.000 .000,00 \text { (dez milhões). }\end{array}$ \\
\hline $\begin{array}{l}\text { Eduardo Leite } \\
\text { Executivo }\end{array}$ & $\begin{array}{l}15 \text { anos e } \\
10 \\
\text { meses }\end{array}$ & $\begin{array}{l}3 \text { anos } \\
\text { (regime } \\
\text { aberto) e } 3 \\
\text { meses em } \\
\text { Regime } \\
\text { fechado. }\end{array}$ & Devolução de $\mathrm{R} \$ 3.234 .115,08$ \\
\hline Julio Gerin & 26 anos & $\begin{array}{l}5 \quad \text { anos } \\
\text { (regime } \\
\text { aberto) }\end{array}$ & $\begin{array}{l}\text { Comprometeu-se a pagar a título de } \\
\text { multa compensatória cível pelos } \\
\text { danos que reconhece causados o } \\
\text { valor de } \mathrm{R} \$ 40.000 .000,00 \\
\text { (quarenta milhões) }\end{array}$ \\
\hline
\end{tabular}




\begin{tabular}{|c|c|c|c|}
\hline $\begin{array}{l}\text { Lobista (Tovo } \\
\text { Setal) }\end{array}$ & & & \\
\hline Mário Goes & $\begin{array}{l}18 \text { anos } \mathrm{e} \\
4 \\
\text { meses }\end{array}$ & $\begin{array}{l}3 \text { anos, } 5 \\
\text { meses } \\
\text { e } 25 \text { dias } \\
\text { (25 dias em } \\
\text { regime } \\
\text { fechado, } \\
\text { com } \\
\text { progressão) }\end{array}$ & $\begin{array}{l}\text { Comprometeu-se a pagar uma } \\
\text { multa compensatória } \\
\text { no valor de } \mathrm{R} \$ 38 \text { milhões. }\end{array}$ \\
\hline $\begin{array}{l}\text { Paulo Roberto } \\
\text { Costa } \\
\text { Burocrata } \\
\text { (ex-diretor de } \\
\text { abastecimento } \\
\text { da Petrobrás) }\end{array}$ & $\begin{array}{l}39 \text { anos e } \\
5 \\
\text { meses }\end{array}$ & $\begin{array}{l}2 \text { anos e } 6 \\
\text { meses }(6 \\
\text { meses em } \\
\text { regime } \\
\text { fechado, } \\
\text { com } \\
\text { progressão) }\end{array}$ & $\begin{array}{l}\text { Renunciou, a título de exemplo, em } \\
\text { favor da União, a qualquer direito } \\
\text { sobre valores mantidos em contas } \\
\text { bancárias e investimentos no } \\
\text { exterior, em qualquer país, inclusive } \\
\text { mantidos no Royal Bank Of Canada } \\
\text { Cayman, aproximadamente USD } \\
2,8 \text { milhões sob os nomes dos } \\
\text { familiares Márcio e Humberto), e os } \\
\text { aproximadamente USD } 23 \text { (vinte e } \\
\text { três) milhões mantidos na Suíça } \\
\text { (em contas de Marici, Paulo } \\
\text { Roberto e Arianna), controladas } \\
\text { direta ou indiretamente, bem como } \\
\text { valores mantidos por meio de } \\
\text { offshores, etc. Vários outros valores } \\
\text { comprometeram-se a pagar a título } \\
\text { de indenização cível, pelos danos }\end{array}$ \\
\hline
\end{tabular}




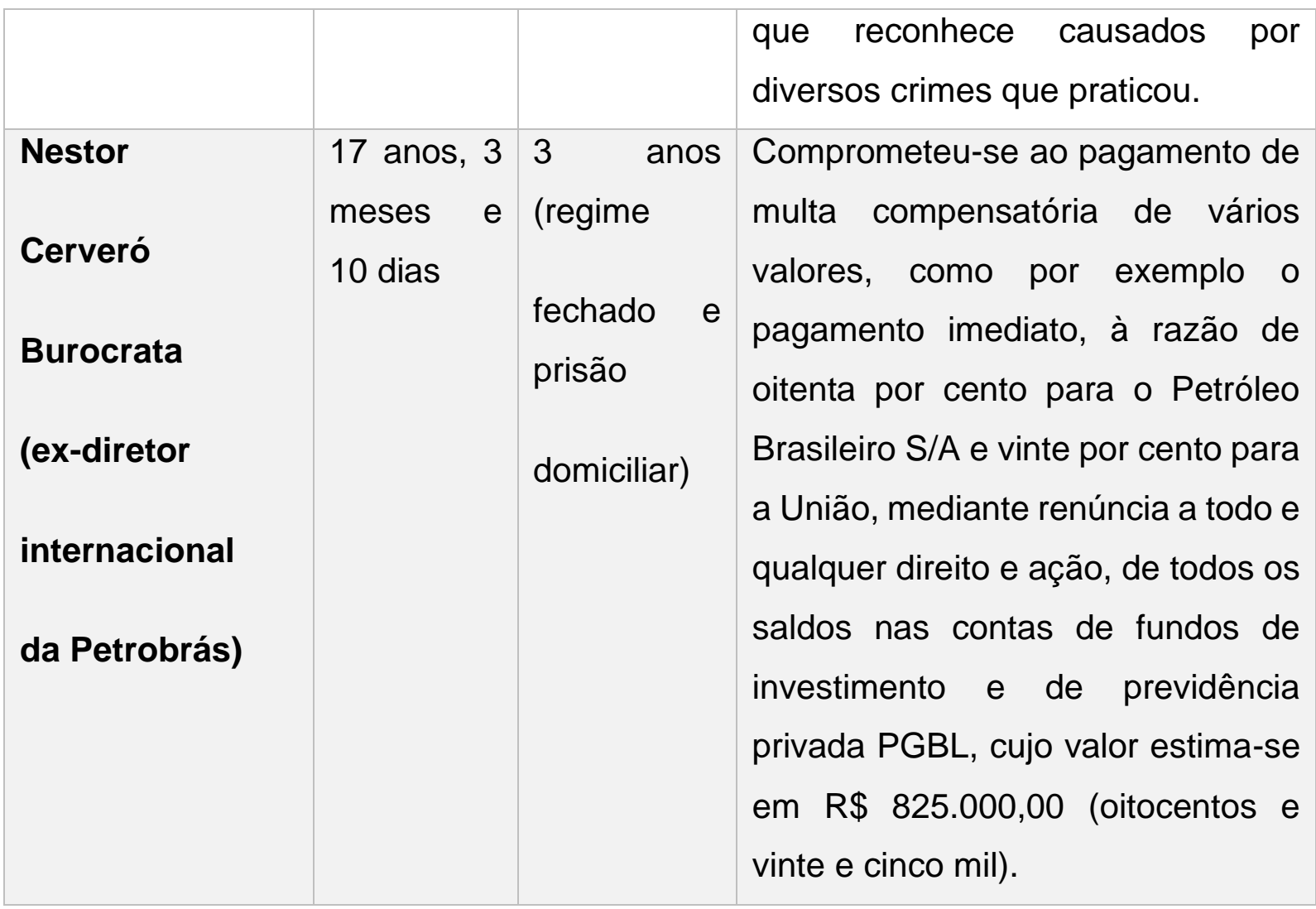

Fonte: Adaptado de Silva, 2017.

A partir da análise do quadro pode-se afirmar que Operação Lava Jato é complexa, e tem demostrado, o quão nocivos são os reflexos da infiltração dos criminosos de colarinho branco, o que tem viabilizado o desvio de valores antes nunca percebidas. Neste sentido, é que se pretende demonstrar, é a importância de um instrumento como a Delação no combate aos crimes praticados, por organizações criminosas, e que vem firmando-se como um mecanismo de investigação e produção de provas e gerando resultados práticos.

Alves e Silva (2017) lembram que, nos termos dos dispositivos da Lei, que tratam da Colaboração Premiada, os acordos não firmam caso as informações pelo colaborador fornecidas não culminem nos resultados estabelecidos pelos dispositivos. Vale ressaltar, que as possíveis condenações não se fundamentarão com base exclusivamente nas palavras do delator. Desse modo, a colaboração constitui tão somente como um dos caminhos possíveis na busca da obtenção de provas, e não um caminho único. 
Neste sentido, Vieira e Morillas (2018), afirmam que isoladamente a colaboração não constitui uma prova suficiente na condenação do réu. Isso é texto previsto da lei, art. $4^{\circ}$, que diz: "Nenhuma sentença condenatória será proferida com fundamento apenas nas declarações de agente colaborador". E continua: A colaboração premiada, como é vista, pela força da lei, é prova, no entanto, meramente indiciária, caso não haja corroboração por outras provas seguras, não tendo qualquer valor para o fim da condenação, devendo assim, o próprio réu admitir participação no crime para colaborar com o processo. Essa é a regra da corroboração.

Assim sendo, Greghi (2007) relata que uma das fragilidades das informações prestadas pelo colaborador, pode desmoronar com o prosseguimento das investigações. Ainda que haja contrárias opiniões, há que reconhecer-se que os avanços obtidos, devido aos acordos já realizados e informações fornecidas pelos colaboradores.

Araújo e Carvalho (2015) relatam a eficácia da colaboração nos acordos realizados que nortearam a investigações que ocasionarão na descoberta de esquemas de lavagem/desvio de dinheiro envolvendo políticos, assim como empresas grandes que participavam de licitações fraudulentas, conseguindo favorecimento diante as demais empresas do processo licitatório. O esquema lesava os cofres públicos a muitos anos.

A base contemporânea do redimensionamento da resposta do Estado diante aos delitos macroeconômicos nos pactos de colaboração celebrados tem como combinação o sistema short-sharp-shock (prisão intensa e curta, mas cumprida efetivamente) com o preceito de reparação dos danos e confisco de tudo que foi ilicitamente ganho (SILVA, 2017).

Segundo Vieira e Morillas (2018), melhor que fixação de uma pena de prisão inútil e longa é a reparação dos danos em razão da vítima que, muitas vezes, o que só espera do sistema é a sua recomposição patrimonial. Fundamental é o confisco também do que foi ganho ilicitamente. Esta combinação de sistemas, segundo o referido autor, atende às três finalidades que a melhor e mais atualizada doutrina atribui ao processo penal moderno: (a) retributivo-preventiva, (b) reparatória e (c) confiscatória. 
Os malefícios relacionados para Camacho e Leal (2015) com a corrupção são enormes, tanto para a sociedade como para o indivíduo, pois negativamente atinge $o$ desempenho econômico do Brasil, na medida em que afeta diretamente as decisões de investimentos, limitando o crescimento econômico, alterando a composição dos gastos, causando distorções na ampla concorrência, abalando confiança no Estado e legitimidade dos governos.

A colaboração premiada nos moldes de hoje segue a vertente de um direito penal do futuro, em que a vítima e a reparação dos danos são alocadas no centro das concepções da teoria do Direito Penal. Portanto, integrou-se pela colaboração na análise do justo, abandonando-se parcela de um efeito punitivo mais drástico em prol do efeito mais próximo do restaurativo, que é a reparação do dano.

\section{CONSIDERAÇÕES FINAIS}

O presente trabalho objetivou demonstrar o instituto da Colaboração Premiada como mecanismo eficaz no combate a corrupção. Os resultados mostram que o enfrentamento das organizações, cada dia avança mais em direção a um direito penal de exceção. A criminalidade organizada, pelas suas características peculiares, exige o uso de meios especiais de investigação ou obtenção de provas.

O estudo verificou que através da Lei 12.830/13, a colaboração sem dúvida trouxe algo inovador no combate estatal do crime organizado. A utilização deste instrumento tem a sua relevância e utilidade no campo da persecução penal, visando ao combate destemido de organizações criminosas, o que é altamente salutar para os interesses da coletividade.

Considerando a ineficácia estatal em acabar com a macro criminalidade, os propósitos das leis são os melhores, com a introdução de mecanismos novos em procura da paz social, segue-se uma nova tendência de política criminal para atender aos anseios e necessidades que emergem da sociedade.

A utilização de acordos de colaboração premiada em inquéritos e processos relacionados a desvios de recursos públicos demonstrou que a delação premiada tem 
eficácia e, sendo uma arma legal no enfrentamento ao crime organizado, sobretudo, criminosos do colarinho branco.

Assim, a delação premiada, tornou-se um forte instrumento de auxílio do Estado no combate a corrupção, apesar da polêmica que paria em torno dela, dada sua grande utilidade e o medo que impera perante a criminalidade crescente, ademais, seus aspectos positivos, superam os negativos, consoante ficou demonstrado.

Portanto, a colaboração, é um poderoso instrumento no combate às organizações, pois ainda na fase da investigação criminal, o colaborador além de confessar os seus crimes, evita a consumação de outros crimes, bem como auxilia a polícia e o Ministério Público nas atividades de recolher as provas contra os demais infratores, possibilitando suas prisões.

\section{REFERÊNCIAS}

AIRES, M. T. A colaboração premiada como instrumento de política criminal: a tensão em relação às garantias fundamentais do réu colaborador. Revista Brasileira de Direito Processual Penal, v. 3, n. 1, 2017.

ALVES, S. P.; SILVA, E. G. da. O instituto da delação premiada como forma de obtenção da verdade. Revista Eletrônica do Programa de Pós, v. 8, n. 2, 2017.

ARAUJO, D. M. de.; CARVAlhO, G. B. V. de. Delação Premiada desafios e perspectivas no Brasil. Artigo de Conclusão de Curso: Universidade Tiradentes UNIT, Aracaju, 2015.

AZEVEDO, L. S. de. Delação premiada à brasileira: algumas questões relacionadas à constitucionalidade e à Eticidade. Trabalho de Conclusão de Curso: Universidade federal do Rio Grande do Norte - UFRN, Natal - RN, 2016.

BITTAR, W. B. Delação Premiada: Direito Estrangeiro, Doutrina e Jurisprudência. 2 ed. Rio de Janeiro: Lumen Juris, 2011. 
BUGARIN, S.; BUGARIN, T. T. S. Ética \& incentivos: Devemos recompensar quem denuncia corrupção? Revista Direito FGV, são Paulo, v. 13, n. 2, p. 390-427, 2017.

CAMACHO, M. G.; LEAL, T. de C. P. V. Lei de organização criminosa: A colaboração premiada e a responsabilidade do Estado na prevenção e combate ao crime organizado. $1^{\circ}$ Simpósio sobre Constitucionalismo, Democracia e Estado de Direito, 2015.

DO CARMO, G.; FÁVERO, L. Os reflexos jurídicos do instituto da delação premiada na persecução penal. 5 Simpósio de Sustentabilidade e Contemporaneidade nas Ciências Sociais, 21 a 23 de junho de 2017.

ESTRÊLA, W. R. G. Delação Premiada: Análise de sua Constitucionalidade. Trabalho de Conclusão de Curso: Faculdade, Taguatinga - DF, 2010.

FREIRE JÚNIOR, A. B. Delação premiada e direitos fundamentais do sujeito passivo da persecução penal a partir da regulamentação constante na Lei 12.850/2013. Revista Eletrônica de Direito Processual - REDP. Rio de Janeiro, v. 18, n. 1, 2017. GREGHI, F. A delação premiada no combate ao crime organizado. Revista de Direito Público, Londrina, v. 2, n. 3, p. 3-24, set./dez. 2007.

GOMES, L. F.; SILVA, M. R. da. Criminalidade Organizada e Justiça Penal Negociada: Delação Premiada. FIDES, Natal, v. 6, n. 1, jan./jun. 2015.

INSERRA, B. N. A delação (Colaboração) Premiada no Brasil. Dissertação de Mestrado: Faculdade de Direito da Universidade de Coimbra, 2018.

NUNES, J. H. G. Delação Premiada como instrumento eficaz de combate ao crime organizado. Trabalho de Pós-Graduação Lato Sensu da Escola da Magistratura do Estado do Rio de Janeiro, 2017.

LUZ, A. M. de A.; et al. A Colaboração Premiada e Processo Penal Brasileiro: Uma análise crítica. VirtuaJus, Belo Horizonte, v. 2, n. 3, p. 176-211, 2017. 
LOPES, R. G. Colaboração Premiada como meio eficaz de combate ao crime organizado. Trabalho de Conclusão de Curso: Universidade de Cuiabá, 2018.

MARCELINO, J. V. O. A colaboração Premiada como mecanismo eficaz no combate às organizações criminosas. Trabalho de Conclusão de Curso: Fundação Universidade Federal de Rondônia - UNIR, Cacoal - RO, 2015.

MENDONÇA, A. B. de. A Colaboração premiada e a nova Lei do Crime Organizado (Lei 12.850/2013). Revista Custos Legis, v. 4, n, 1, 2013.

POLICIA FEDERAL. Ações da PF contra corrupção crescem $411 \%$ em cinco anos. Correio Brasiliense, 2018.

SANTOS, L. A. P.; ROCHA, G. G.; VIALI, F. C. A. A eficácia do instituto da colaboração/delação premiada no combate ao crime organizado brasileiro. Revista Semana Acadêmica, v, 145, n, 1, 2018.

SILVA, M. R. da. A colaboração premiada como terceira via do direito penal no enfrentamento à corrupção administrativa organizada. Revista Brasileira de Direito Processual Penal, vol. 3, n. 1, 2017.

SILVA, A. V. da.; BORGES, D. M. Enfrentamento do crime organizado por meio da delação premiada. Rev. de Criminologias e Politicas Criminais, Porto Alegre, v. 4, n. 2, 2018.

TEIXEIRA, G. N. L. A Colaboração Premiada como Instrumento do Ministério Público no Combate às Organizações Criminosas. Cadernos do Ministério Público do Estado do Ceará, 2016.

VASCONCELLOS, V. G. de. Colaboração Premiada no Processo Penal. 1 ed. Editora revista dos Tribunais, 2017.

VIEIRA, R. D.; MORILLAS, J. P. Do Instituto da Delação Premiada: Conceito, abordagem comparativa alienígena, evolução legislativa no brasil e posicionamentos 
doutrinários. Revista de Direito Penal, Processo Penal e Constituição, Salvador, v. 4, n. 1, 2018.

Enviado: Outubro, 2020.

Aprovado: Novembro, 2020. 